\title{
Acceptability of a COVID-19 vaccine and role of knowledge, attitudes and beliefs on vaccination willingness among medical students
}

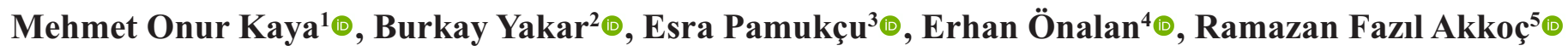 \\ , Edibe Pirinçci ${ }^{6}$, Mehmet Ferit Gürsu ${ }^{7}$
}

${ }^{1}$ Department of Biostatistics and Medical Informatics, Firat University Faculty of Medicine, Elazığ, Turkey

${ }^{2}$ Department of Family Medicine, Firat University Faculty of Medicine, Elazı̆̆, Turkey

${ }^{3}$ Department of Statistics, Firat University, Institute of Natural and Applied Sciences, Elazlğ, Turkey

${ }^{4}$ Department of Internal Medicine, Firat University Faculty of Medicine, Elazı̆̆, Turkey

${ }^{5}$ Department of Public Health, Firat University Faculty of Medicine, Elazığ, Turkey

${ }^{6}$ Department of Anatomy, Firat University Faculty of Medicine, Elazığ, Turkey

${ }^{7}$ Department of Biochemistry, Firat University Faculty of Medicine, Elazı̆g, Turkey

\section{ABSTRACT}

Objectives: Vaccination to the population is the most effective way to get rid of the COVID-19 pandemic, which currently has no effective treatment. For the high vaccine acceptance rate, it is important to determine the vaccine willingness of individuals and the barriers to vaccination. We aimed to determine the acceptability of the COVID-19 vaccine and the effect of attitudes, perception and beliefs on vaccination willingness among medical students.

Methods: In February 2020, a cross-sectional survey was conducted online among medical student. A total of 734 medical students out of 980 medical students answered the questionnaire forms (response rate: $75.4 \%$ ). The online questionnaire collected socio-demographic characteristics, attitudes, risk perception and beliefs about the COVID-19 pandemic and vaccine. Vaccine hesitancy, rejection and acceptance were determined by self-report of medical students.

Results: Total of 739 medical students included study. Students declared that $60.1 \%(n=444)$ of them to be willing to vaccinated, $14.2 \%(\mathrm{n}=105)$ refused and $25.7 \%(\mathrm{n}=190)$ were not sure. Covid-19 willingness to be vaccinated was higher in female $(p=0.005)$, clinical students $(p<0.001)$, those who ever tested for COVID$19(p=0.002)$, those who had covid-19 infection history in the family $(p=0.043)$, those who had COVID-19 and COVID-19 vaccine education $(p=0.001)$. Positive attitudes skor and higher knowledge scores were related with highly willingness to be vaccinated. High beliefs score (positive beliefs) was found to be associated with a higher willingness to be vaccinated $(p<0.001)$.

Conclusions: Although the majority of the study population willingness to be vaccinated, one-third of medical students are hesitant about vaccination. Education, positive attitude and beliefs are related to higher willingness to vaccination. The COVID-19 pandemic immunization programs should be designed to remove barriers to negative vaccine beliefs and perception.

Keywords: COVID-19 vaccines, medical students, vaccination awareness, perception, beliefs 
$\mathrm{C}$ oronavirus diseases 2019 (COVID-19) caused by the new type of coronavirus (SARS-COV2) was first reported in December 2019. It caused a pandemic in a short time and posed a significant threat to the whole world. Despite more than 1 year, humanity still suffers from COVID-19. Although more than 114 million cases have caused more than 2.5 million deaths worldwide, an effective treatment against COVID-19 has still not been found [1,2].

The COVID-19 pandemic has caused disruptions in almost all areas of life all over the world. Education, especially medical education, is one of the areas negatively affected by the pandemic. Medical schools have been suspended during the pandemic, and as such, many students are stayed at home. This has disrupted the medical education process. Currently, medical education is tried to be given online in Turkey. There have been problems in bedside and practical training with online medical education. Although time is needed to accurately predict the effects of the pandemic on education, it is predicted that it may pose important problems for the learning experience and professional development of medical students [3].

It is known that the most beneficial method for the whole world to get rid of the negative effects of the pandemic is vaccination against COVID-19. It is possible with vaccination on the return of medical education and medical faculty students to normal life [4]. The tickets of medical education and medical faculty students to return to normal life pass from vaccination. Although vaccination seems to be the way out of the pandemic, the willingness of individuals to be vaccinated is also important in combating the pandemic. During the 2009 influenza A (H1N1) pandemic, it has reported that the acceptability of influenza vaccination among adults in the USA was between 50-64\%. However, there is not enough information in the literature about the COVID-19 vaccine acceptance and the factors affecting it. Such information which acceptance rate and affecting factors are may be useful for improving COVID-19 vaccine acceptability $[5,6]$.

The current study was aimed to determine COVID-19 vaccine acceptance and which factors are related vaccination willingness

\section{METHODS}

Study Design, Population and Sampling
We conducted a prospective cross-sectional online survey study about COVID-19 vaccination with medical students in February 2021. The study population consisted of Firat University all medical students. Online questionnaire forms were sent to the all medical students by whats-app. A total of 980 medical students who study in the period of 2020-2021 constituted the study population. Online questionnaire forms were sent to all medical students by whats-app, not using the sampling method. A total of 739 medical students who answered the questionnaire forms were included in the study (response rate:75.4\%). Before applying the questionnaire, participants were asked to accept a consent form containing statements about the purpose of the study and voluntary participation of the questionnaire, and those who non-volunteers could not answer the questionnaire. The online questionnaire was sent 3 times with one week intervals and students who did not answer were asked to answer. After three weeks, unreturned questionnaires were recorded as missing. Those under the age of 18 years old, foreign students and those who are not active students were excluded from the study.

\section{Ethical approval, informed consent and permissions}

The study was approved by the Firat University Non-Interventional Ethics Committee (Approval code: 23/128/2019), and the World Medical Association Declaration of Helsinki guidance was followed. The consent of the participants was questioned with the first question of the online survey form. The questionnaire was terminated for the participants who did not declare consent to participate in the study. In addition, permission was obtained from the scientific research platform of the Turkish Ministry of Health.

\section{Measures}

The online questionnaire was designed based on previous studies which are assess vaccine acceptance. The contents of the questionnaire included (1) sociodemographic characteristics, such as; age, sex, class, family income, health status, personal and family history of COVID-19 diagnosis (2) perception and attitudes about COVID-19 pandemic; (3) beliefs about COVID-19.

We developed perception, attitude and beliefs survey items on vaccination based on previous literature data and Turkish Ministry of health suggestions for Avoiding and preventing COVID-19. Questionnare 
prepared in local language Turkish. First, a group of medical experts provided feedback on the items of the survey, where it was modified as per their comments. Next, the modified draft of the survey went through pilot testing on 30 participants to provide feedback about the clarity and comprehensibility of the items of the survey. The questionnaire was revised one more time, after feedback of the students, and then applied to the study population

\section{Perception and Attitudes}

We assessed participants' perceptions about COVID-19 by calculating the score of three items answered by participants (possible range $=1-4$ ). The perceptions questions are: perceived likelihood of getting a COVID-19 infection in the future (possibility range $=1-4$ ), disease progress in case of covid-19 (severity range $=1-4$ ), how threatening covid-19 is for you (serious range $=1-4$ ). We assessed participants' attitudes about COVID-19 by calculating the score of six items answered by participants (possible range $=0-1$ ). Washing your hands ( $1=$ rarely, $4=$ always $)$, Using hand sanitizer or cologne $(1=$ rarely, $4=$ always $)$, Wearing a mask ( $1=$ rarely, $4=$ always $)$, Social distancing $(1=$ rarely, 4= always), Staying away from closed area (1 $=$ rarely, $4=$ always), and follow the recommended guidelines for COVID-19 ( 1 = rarely, 4 = always). Total score of perception and attitudes include eight questions. Participants could get a minimum of 8 and a maximum of 32 points. We coded each variable so that higher values indicate greater levels of positive perception and attitudes [7-9].

\section{Beliefs about COVID-19}

We assessed participants' perceptions about COVID-19 by calculating the score of five items answered by participants (possible range $=1-5$ ). The beliefs questions are: difficulty to get vaccinated (possible range $=1-5$ ); effectiveness of a COVID-19 vaccine personality (possible range $=1-5$ ); effectiveness of a COVID-19 vaccine for your family (possible range $=1-5$ ); effectiveness of a COVID-19 vaccine for public health (possible range $=1-5$ ); potential harms of a COVID-19 vaccine (possible range $=1-5$ ). Total score of beliefs include five questions. Participants could get a minimum of 5 and a maximum of 25 points. We coded each belief variable so that higher values indicate greater levels of positive beliefs $[7,8]$

\section{Statistical Analysis}

Statistical analysis of the data was performed by IBM SPSS 22 statistics package program. Kolmogorov-Smirnov test was used to determine whether the data showed normal distribution. Descriptive statistics of the data were expressed as mean \pm standard deviation for variables with normal distribution in continuous data and frequency for categorical variables as percentage (n (\%)). Pearson Chi-square test was used to analyse categorical data. In comparison of more than two independent groups, One-Way ANOVA and LSD test for post-Hoc test were used for normal distributed continuous data. Significance level was $p$ $<0.05$. Statistically significant significance values are indicated in bold in the tables.

\section{RESULTS}

Total of 739 medical students included study. The mean age of the students were $21.20 \pm 2.68$ years. The sample was $57 \%$ female, preclinical $(65.3 \%)$ and clinical $(34.7 \%$ ) students. Students declared that $60.1 \%$ (n $=444)$ of them to be willing to vaccinated, $14.2 \%$ (n $=105)$ refused and $25.7 \%(n=190)$ were not sure. COVID-19 willingness to be vaccinated was higher in female $(p=0.005)$, clinical students $(p<0.001)$, those who ever tested for COVID-19 $(p=0.002)$, those who had covid-19 infection history in the family ( $p=$ 0.043), those who had COVID-19 and COVID-19 vaccine education $(p=0.001)$ (Table 1$)$.

Covid-19 willingness to be vaccinated was higher in students who declared that "I have a high possibility of getting COVID-19 in the future" $(p<0.001)$, "it can cause high progressive disease" $(p=0.008)$ and "highly threatening for my health" $(p<0.001)$. Positive attitudes skor and higher total knowledge and attitudes scores were related with highly willingness to be vaccinated (Table 2 ).

The relationship between students' beliefs on the COVID-19 vaccine and their willingness to be vaccinated is presented in Table 3. High beliefs score (positive beliefs) was found to be associated with a higher willingness to be vaccinated $(p<0.001)$ (Table 3$)$.

\section{DISCUSSION}

The current study showed that $60.1 \%(n=444)$ of 
Table 1. Association of demographic characteristics and COVID-19 vaccine willingness

\begin{tabular}{|c|c|c|c|c|c|}
\hline \multicolumn{6}{|c|}{ Do you willing to get the COVID-19 vaccine } \\
\hline Variables & No & Yes & Hesidant & Total & $p$ value \\
\hline \multicolumn{6}{|l|}{ Gender } \\
\hline Female & $47(44.8)$ & $274(61.7)$ & $106(55.8)$ & $427(57.8)$ & 0.005 \\
\hline Male & $58(55.2)$ & $170(38.3)$ & $84(44.2)$ & $312(42.2)$ & \\
\hline \multicolumn{6}{|c|}{ Education level in medical school } \\
\hline First year & $37(35.2)$ & $89(20.0)$ & $69(36.3)$ & $195(26.4)$ & $<0.001$ \\
\hline Second year & $29(27.6)$ & $84(18.9)$ & $66(37.4)$ & $179(24.2)$ & \\
\hline Third year & $12(11.4)$ & $61(13.7)$ & $36(18.9)$ & $109(14.7)$ & \\
\hline Fourth year & $18(17.1)$ & $70(15.8)$ & $7(3.7)$ & $95(12.9)$ & \\
\hline Fifth year & $3(2.9)$ & $71(16.0)$ & $11(5.8)$ & $85(11.5)$ & \\
\hline Internship & $6(5.7)$ & $69(15.5)$ & $1(0.5)$ & $76(10.3)$ & \\
\hline
\end{tabular}

Do you have any chronic disease?

$\begin{array}{lccccc}\text { No } & 95(90.5) & 410(92.3) & 171(90.0) & 676(91.5) & 0.579 \\ \text { Yes } & 10(9.5) & 34(7.7) & 19(10.0) & 63(8.5) & \end{array}$

How would you describe your health condition?

$\begin{array}{lcccc}\text { Very bad } & 1(1.0) & 3(0.7) & 2(1.1) & 6(0.8) \\ \text { Bad } & 6(5.7) & 30(6.8) & 14(7.4) & 50(6.8) \\ \text { Good } & 67(63.8) & 335(75.5) & 148(77.9) & 550(74.4) \\ \text { Very good } & 31(29.5) & 76(17.1) & 26(13.7) & 133(18.0)\end{array}$

Ever tested for COVID-19

$\begin{array}{llllll}\text { No } & 84(80.0) & 310(69.8) & 156(82.1) & 550(74.4) & \mathbf{0 . 0 0 2} \\ \text { Yes } & 21(20.0) & 134(30.2) & 34(17.9) & 189(25.6) & \end{array}$

\section{Personal history of COVID-19 diagnosis}

$\begin{array}{llcccc}\text { No } & 89(84.8) & 389(87.6) & 164(86.3) & 642(86.9) & 0.714 \\ \text { Yes } & 16(15.2) & 55(12.4) & 26(13.7) & 97(13.1) & \end{array}$

Family member/friend ever diagnosed with COVID-19

$\begin{array}{llllll}\text { No } & 72(68.6) & 256(57.7) & 102(53.7) & 430(58.2) & \mathbf{0 . 0 4 3} \\ \text { Yes } & 33(31.4) & 188(42.3) & 88(46.3) & 309(41.8) & \end{array}$

Have you ever been quarantined for COVID-19?

$\begin{array}{llllll}\text { No } & 79(75.2) & 307(69.1) & 140(73.7) & 526(71.2) & 0.313 \\ \text { Yes } & 26(24.8) & 137(30.9) & 50(26.3) & 213(28.8) & \end{array}$

\section{Education for COVID-19}

$\begin{array}{lllccc}\text { No } & 42(40.0) & 139(31.3) & 88(46.3) & 269(36.4) & \mathbf{0 . 0 0 1} \\ \text { Yes } & 63(60.0) & 305(68.7) & 102(53.7) & 470(63.6) & \end{array}$

\section{Education for COVID-19}

\begin{tabular}{lccccc} 
No & $83(79.0)$ & $351(79.1)$ & $173(91.1)$ & $607(82.1)$ & $\mathbf{0 . 0 0 1}$ \\
Yes & $22(21.0)$ & $93(20.9)$ & $17(8.9)$ & $132(17.9)$ & \\
\hline
\end{tabular}

Data are shown as n (\%). 
Table 2. Relation between perception and attitude score and COVID-19 vaccine willingness

\begin{tabular}{|c|c|c|c|c|}
\hline \multirow[b]{2}{*}{ Perception and Attitudes } & \multicolumn{4}{|c|}{ Do you willing to get the COVID-19 vaccine } \\
\hline & No & Yes & Hesidant & $p$ value* \\
\hline $\begin{array}{l}\text { What are your possibility of getting COVID-19 } \\
\text { in the future? }\end{array}$ & $2.75 \pm 0.69^{b}$ & $3.60 \pm 0.58^{\mathrm{a}}$ & $3.02 \pm 0.63^{\mathrm{a}}$ & $<0.001$ \\
\hline $\begin{array}{l}\text { How do you think the disease will progress if } \\
\text { you get COVID-19 in the future? }\end{array}$ & $2.37 \pm 0.84^{\mathrm{b}}$ & $2.55 \pm 0.70$ & $2.66 \pm 0.84^{\mathrm{a}}$ & 0.008 \\
\hline How threatening is COVID-19 to your health? & $2.48 \pm 0.91^{\mathrm{b}}$ & $2.85 \pm 0.73^{\mathrm{a}}$ & $2.87 \pm 0.76^{\mathrm{a}}$ & $<0.001$ \\
\hline $\begin{array}{l}\text { Washing your hands often, especially after } \\
\text { being in a public place or after blowing your } \\
\text { nose, coughing, or sneezing. }\end{array}$ & $2.92 \pm 0.98$ & $3.09 \pm 0.89$ & $3.02 \pm 0.89$ & 0.204 \\
\hline $\begin{array}{l}\text { Using hand sanitizer or cologne that contains at } \\
\text { least } 60 \% \text { alcohol. }\end{array}$ & $2.81 \pm 1.11^{\mathrm{b}}$ & $3.16 \pm 0.90^{\mathrm{a}}$ & $3.01 \pm 0.95$ & 0.001 \\
\hline Wearing a mask when going out in public. & $3.57 \pm 0.76^{b}$ & $3.87 \pm 0.38^{\mathrm{a}}$ & $3.74 \pm 0.59^{\mathrm{a}}$ & $<0.001$ \\
\hline $\begin{array}{l}\text { Social distancing (keeping about } 2 \text { meters } \\
\text { between yourself and other people) }\end{array}$ & $2.52 \pm 0.88$ & $2.62 \pm 0.82$ & $2.61 \pm 0.83$ & 0.584 \\
\hline $\begin{array}{l}\text { Staying away from closed area (situations close } \\
\text { contact with others) }\end{array}$ & $2.75 \pm 0.88$ & $2.70 \pm 0.84$ & $2.62 \pm 0.86$ & 0.371 \\
\hline $\begin{array}{l}\text { Do you think you follow the recommended } \\
\text { guidelines for COVID-19 adequately? }\end{array}$ & $3.00 \pm 0.76$ & $3.09 \pm 0.68$ & $2.69 \pm 0.79$ & 0.121 \\
\hline Total score & $22.18 \pm 4.31^{b}$ & $23.90 \pm 3.28^{\mathrm{a}}$ & $23.53 \pm 3.72^{\mathrm{a}}$ & $<0.001$ \\
\hline
\end{tabular}

Data are shown as mean \pm standard deviation.

Higher scores indicate greater levels of positive attitudes and high kowledge.

* One-way Anova test

${ }^{\mathrm{a}-\mathrm{b}}$ Pairwise comparisons

participants to be willing to vaccinated, $14.2 \%(\mathrm{n}=$ $105)$ refused and $25.7 \%$ (190) were not sure. The current study showed that more than a third of medical students were undecided about COVID-19 vaccination. Lucia et al. [7] reported that 53\% of medical students would participate in a COVID-19 vaccine trial and $23 \%$ were unwilling to take a COVID-19 vaccine. A previous study reported that $69 \%$ of participants were willing to get a COVID-19 vaccine among US adults [8]. Another study reported that $91.3 \%$ of the participants would accept vaccination after the vaccine becomes available, among $52.2 \%$ of them wanted to get vaccinated as soon as possible, while others $47.8 \%$ would delay the vaccination until the vaccine's safety was confirmed [10]. It can be said that individuals still have hesitancy against the vaccine, which is the most important weapon we have to get rid of the pandemic. In the study conducted during the influenza A(H1N1) pandemic period, the vaccination rate was reported as $93.2 \%$ in medical students and $84.8 \%$ in nursing students [11]. Compared to the high acceptance vaccine rate in the previous pandemic, the current COVID-19 vaccines hesitancy rate is unacceptable. It can be suggested to remove the obstacles to the willingness to be vaccinated as soon as possible.

The current study showed that sociodemographic factors such as gender, education level, family history of covid-19 diagnosis and having education for COVID-19 and COVID-19 vaccine are related to vaccine willingness and acceptance. Studies examining the relationship between COVID-19 vaccination willingness and sociodemographic characteristics are limited in the literature. A systematic review study reported that age, sex, occupation and educational level are associated with influenza $\mathrm{A}(\mathrm{H} 1 \mathrm{~N} 1)$ vaccination during the pandemic [12]. Wang et al. [10] reported that being male and believing in the efficacy of COVID-19 vaccination increase the probability of accepting COVID-19 vaccination. The striking finding in our data was that the willingness to be vaccinated was higher in students who declared having COVID19 education and COVID-19 vaccine education. 
Table 3. Relation between Beliefs score and COVID-19 vaccine willingness

\begin{tabular}{|c|c|c|c|c|}
\hline \multirow[b]{2}{*}{ Beliefs about COVID-19 vaccination } & \multicolumn{4}{|c|}{ Do you willing to get the COVID-19 vaccine } \\
\hline & No & Yes & Hesidant & $p$ value* \\
\hline $\begin{array}{l}\text { If you have to paid for the vaccine. Does this } \\
\text { affect your vaccine acceptance? }\end{array}$ & $1.86 \pm 0.77^{\mathrm{b}}$ & $4.52 \pm 0.58^{\mathrm{a}}$ & $3.19 \pm 0.49^{\mathrm{a}}$ & $<0.001$ \\
\hline $\begin{array}{l}\text { If you decide to get the COVID-19 vaccine, do } \\
\text { you think it would be hard to getting the } \\
\text { vaccine? }\end{array}$ & $3.41 \pm 1.12$ & $3.47 \pm 1.14^{\mathrm{a}}$ & $3.12 \pm 0.89^{b}$ & 0.001 \\
\hline $\begin{array}{l}\text { How is important do you think the getting } \\
\text { vaccine is to protect your health? }\end{array}$ & $3.00 \pm 1.04^{\mathrm{b}}$ & $4.41 \pm 0.67^{\mathrm{a}}$ & $3.75 \pm 0.86^{\mathrm{a}}$ & $<0.001$ \\
\hline $\begin{array}{l}\text { How important do you think vaccination is in } \\
\text { protecting the health of your family members? }\end{array}$ & $3.09 \pm 1.18^{\mathrm{b}}$ & $4.46 \pm 0.72^{\mathrm{a}}$ & $3.82 \pm 0.91^{\mathrm{a}}$ & $<0.001$ \\
\hline $\begin{array}{l}\text { How important vaccination is in protecting public } \\
\text { health and combating COVID- } 19 \text { pandemic. }\end{array}$ & $3.31 \pm 1.05^{\mathrm{b}}$ & $4.61 \pm 0.57^{\mathrm{a}}$ & $3.93 \pm 0.84^{\mathrm{a}}$ & $<0.001$ \\
\hline $\begin{array}{l}\text { Do the possible side effects of the COVID-19 } \\
\text { vaccine affect your vaccine acceptance? }\end{array}$ & $2.16 \pm 0.81^{b}$ & $2.56 \pm 0.83^{\mathrm{a}}$ & $2.37 \pm 0.77$ & $<0.001$ \\
\hline Total score & $16.83 \pm 3.77^{\mathrm{b}}$ & $24.03 \pm 2.51^{\mathrm{a}}$ & $20.19 \pm 2.69^{a}$ & $<0.001$ \\
\hline
\end{tabular}

Data are shown as mean \pm standard deviation.

Higher scores indicate greater levels of positive beliefs.

* One-way Anova test

${ }^{\mathrm{a}-\mathrm{b}}$ Pairwise comparisons

${ }^{1} 1$ item; 5-point response scale ranging from " absolutely affects" to " absolutely does not affect" (possible range = 1-5)

21 item; 5-point response scale ranging from "very hard" to "very easy"(possible range=1-5)

3,4,5 1 item; 5-point response scale ranging from "unimportant" to "very important" (possible range=1-5)

${ }^{6} 1$ item; 5-point response scale ranging from " absolutely affects" to " absolutely does not affect" (possible range = 1-5)

Based on our data, we can say that we should attach importance to education in order to increase the willingness to be vaccinated.

Previous studies showed that risk perception is a central predictor of protection intentions and preventive health behaviours [13]. In addition, it is known that vaccination rates are higher in those who have a positive attitude towards the disease [14]. According to our study, the willingness to be vaccinated was higher in the participants who had a positive attitude and having a high-risk perception. A COVID-19 vaccine acceptance study reported that the COVID-19 vaccine acceptance rates were lower in those with an anti-vaccination attitude and those with low-risk perception. The current study and previous vaccine acceptance studies showed that positive attitude and perception are important to vaccine acceptance. It was thought that we should increase the positive attitudes of individuals for vaccination in the fight against the COVID-19 pandemic and the pandemics that may be experienced from now on.

Health beliefs are associated with adherence to preventive healthcare and treatment. People will not change their health behaviours unless they believe that they are at risk. Previous studies reported taht several health beliefs were also correlated with vaccine acceptability (i.e. perceived likelihood, perceived severity, perceived vaccine effectiveness, perceived potential vaccine harms) [7, 8, 10-14]. In our study, we showed once again that beliefs about the vaccine are associated with vaccination rates. Negative beliefs that especially the vaccine is not protective and the vaccine has side effects and harmful effects were found to be related to the willingness to be vaccinated in our study. Family physicians who are at the forefront of vaccine practice in Turkey, should pay attention to these negative beliefs and they must struggle to change these negative thoughts.

\section{Implications}

This study showed us that even though we were in the pandemic process, individuals' low knowledge, negative attitudes and beliefs decreased their willingness to be instilled. This study showed that even dur- 
ing the pandemic period, which has no current treatment, causes thousands of deaths every day, negatively affects all of life, and we know that vaccination is the only way to escape from the pandemic, but still, individuals experience vaccination hesitation.

\section{Limitations}

We conducted cross-sectional study among medical student so obtained data may not reflect the adult population vaccination willingness. We did not use objective measurement methods for attitudes and beliefs about vaccine willingness. All data are obtained from participants' own declaration. Vaccination against COVID-19 has not yet become widespread in our country, and the lack of sufficient data about the COVID-19 vaccine may have affected the opinions of individuals about the vaccine.

\section{CONCLUSION}

Although the majority of the study population willingness to be vaccinated, one-third of medical students are hesitant about vaccination. Education, positive attitude and beliefs are related to higher willingness to vaccination. Future studies in this area should focus on the effect of vaccine education and attempts to change attitude and belief on vaccine acceptance. The COVID-19 pandemic immunization programs should be designed to remove barriers to negative vaccine beliefs and perception.

\section{Authors' Contribution}

Study Conception: MOK, BY; Study Design: MOK, BY, EO, EP; Supervision: BY, EP, MFG; Funding: NTA, AK; Materials: MOK, BY, EO, RFA; Data Collection and/or Processing: MOK, BY, EO, RFA; Statistical Analysis and/or Data Interpretation: MOK, EP, BY; Literature Review: BY, EO, MOK; Manuscript Preparation: BY, MOK, EP and Critical Review: EP, MFG, BY.

\section{Conflict of interest}

The authors disclosed no conflict of interest during the preparation or publication of this manuscript.

\section{Financing}

The authors disclosed that they did not receive any grant during the conduction or writing of this study.

\section{REFERENCES}

1. Huang C, Wang Y, Li X, Ren L, Zhao J, Hu Y, et al. Clinical features of patients infected with 2019 novel coronavirus in Wuhan, China. Lancet 2020;395:497506.

2. World Health Organization. WHO Coronavirus Disease (COVID-19) Dashboard. Available online: https://covid19.who.int/?gclid=EAIaIQobChMI2_CM 6eDZ6gIVghh9Ch3nDQm1EAAYASAAEgLqwPD_ BwE

3. Sani I, Hamza Y, Chedid Y, Amalendran J, Hamza N. Understanding the consequence of COVID-19 on undergraduate medical education: Medical students' perspective. Ann Med Surg (Lond) 2020;58:117-9.

4. Bish A, Michie S. Demographic and attitudinal determinants of protective behaviours during a pandemic: a review. $\mathrm{Br} J$ Health Psychol 2010;15(Pt4):797-4.

5. Gidengil CA, Parker AM, Zikmund-Fisher BJ. Trends in risk perceptions and vaccination intentions: A longitudinal study of the first year of the H1N1 pandemic. Am J Public Health 2012;102:672-9.

6. Horney JA, Moore Z, Davis M, MacDonald PD. Intent to receive pandemic influenza $A(H 1 N 1)$ vaccine, compliance with social distancing and sources of information in NC, 2009. PLoS ONE 2010;5:e11226.

7. Lucia VC, Kelekar A, Afonso NM. COVID-19 vaccine hesitancy among medical students. J Public Health (Oxf) 2020 Dec 26:fdaa230.

8. Reiter PL, Pennell ML, Katz ML. Acceptability of a COVID-19 vaccine among adults in the United States: How many people would get vaccinated? Vaccine 2020;38:6500-7.

9. Yakar B, Ozturk Kaygusuz T, Pirincci E, Onalan E , Ertekin Y . Knowledge, attitude and anxiety of medical students about the current COVID-19 outbreak in Turkey. Fam Pract Palliat Care 2020;5:36-44.

10. Wang J, Jing R, Lai X, Zhang H, Lyu Y, Knoll MD, Fang H. Acceptance of COVID-19 vaccination during the COVID-19 pandemic in China. Vaccines (Basel) 2020;8:482.

11. Faresjö T, Arvidsson L, Boberg P, Hagert B, Gursky EA, Timpka T. Swedish nursing and medical students' high vaccination adherence during the influenza A (H1N1) pandemic 2009: insights for pan- 
demic preparedness. Scand J Infect Dis 2012;44:237- cination uptake in medical students. Vaccine 41. 2012;30:1143-8.

12. Brien S, Kwong JC, Buckeridge DL. The determinants of 2009 pandemic A/H1N1 influenza vaccination: a systematic review. Vaccine 2012;30:1255-64. 14. Walker L, Newall A, Heywood AE. Knowledge, attitudes and practices of Australian medical students 13. Betsch C, Wicker S. E-health use, vaccination towards influenza vaccination. Vaccine 2016;34:6193knowledge and perception of own risk: drivers of vac9. 